\title{
Exclusive Breast Feeding Prevalence and Associated Factors an Institutional Based Cross Sectional Study in Bahir dar Northwest Ethiopia
}

\author{
Ewnetu Bazie $^{1}$, Amsalu Birara ${ }^{2,}$, Ewenat G/hanna ${ }^{3}$ \\ ${ }^{1}$ Amhara Regional State Health Bureau, Bahir Dar, Ethiopia \\ ${ }^{2}$ Department of Environmental Health, School of public Health Collage of Medicine and Health Science, Bahir Dar University, Bahir Dar, \\ Ethiopia \\ ${ }^{3}$ Department of General Master of Public Health, Addis Continental Institute of Public Health (ACIPH), Addis Ababa, Ethiopia
}

\author{
Email address: \\ ewnetubazie@gmail.com (E. Bazie), amsalubirara@yahoo.com (A. Birara), amsalub@bdu.edu.et (A. Birara), \\ gewenat@gmail.com (E. G/hanna) \\ ${ }^{*}$ Corresponding author
}

\section{To cite this article:}

Ewnetu Bazie, Amsalu Birara, Ewenat G/hanna. Exclusive Breast Feeding Prevalence and Associated Factors an Institutional Based Cross Sectional Study in Bahir dar Northwest Ethiopia. International Journal of Homeopathy \& Natural Medicines. Vol. 5, No. 1, 2019 , pp. $42-49$. doi: 10.11648/j.ijhnm.20190501.17

Received: January 24, 2019; Accepted: March 8, 2019; Published: July 15, 2019

\begin{abstract}
Exclusive breastfeeding is accepted as the best natural form of infant feeding up to six months and has a protective effect against morbidity and mortality. The objective of this study is to assess the prevalence of exclusively breastfeeding and associated factors during the first six months among mothers who was attending in Bahir Dar public health centers and private pediatric clinics. An institutional based cross-sectional study was conducted on mothers with infants sixtwelve months of age. Multi-stage sampling technique was used to determine the final sample size of 634 participants. Systematic random sampling technique was used to select the eligible mothers. The result show that, The overall rates of exclusively breast feeding were $46.7 \%$. Mothers who are currently in union [ $\mathrm{AOR}=0.176(0.058,0.536)]$, urban residence mothers $[(\mathrm{AOR}=0.375(0.211,0.664)]$, not sick infants $[(\mathrm{AOR}=4.441(2.404,8.094)]$, adequate knowledgeable mothers $[(\mathrm{AOR}=3.570(2.367,5.383)]$ and favorable attitude mothers $[(\mathrm{AOR}=2.537(1.729,3.724)]$ were significant association towards exclusively breast feeding. Exclusively breast feeding was significantly low in Bahir Dar city administration health care facility attendant mothers.. Therefore health education should be focused on urban societies, mothers with sick infants, to raise their knowledge and change attitude of mothers towards the many benefit of exclusive breast feeding both in public and private health care facilities so as to increase the prevalence of exclusive breast feeding.
\end{abstract}

Keywords: Breast Feeding Prevalence, Breast Feeding Practices, Associated Factors

\section{Introduction}

Exclusive breastfeeding is accepted as the best natural form of infant feeding up to six months and has a protective effect against morbidity and mortality. Exclusive breastfeeding (EBF) for the first six months of an infant's life is a cost effective intervention in saving children's lives and it is recommended by the World Health Organization (WHO) [2]. It is estimated that, with exclusive breast feeding coverage of $90 \%, 13$ to $15 \%$ of deaths of children under 5 years could be averted in low and middle income countries [8]. In areas where HIV prevalence is high, especially in subSaharan Africa, exclusive breast feeding has been showed to have an added advantage of reducing the rates of mother-tochild transmission of HIV (MTCT) [8-11]. But due to the perception of breast feeding makes the breast big and makes abnormal posture, poor awareness of the many benefit of exclusive breast feeding, the future fear of the infant not used bottle feed, majority of the mothers do not want to breast feed consistently to their infant. A study conducted in Ethiopia in 2009, reveled to the prevalence of exclusively 
breast feeding during the first six months was $49 \%$ and infant mortality was $77 / 1000$ births [5]. Currently according to the EDHS (2011) survey the prevalence of exclusively breast feeding was $52 \%$ and the infant mortality rate showed $59 / 1000$ births [4]. The low prevalence of exclusively breastfeeding in most developing countries including Ethiopia is attributed to various maternal and child factors such as place of residence, sex and age of the child, mother working outside home, maternal age and low educational level, low access to mass media and low economic status by several researchers $[5,6]$. In an effort to gain a better understanding of an under researched topic in Bahirdar health care facilities, this study will investigate the prevalence and factors affecting exclusively breastfeeding during the first sex moths by means of cross-sectional study.

\section{Methods}

\subsection{Study Area}

The study area was Bahir Dar city administration located in Northwest Ethiopia. It is the capital of the Amhara region, located about 563 kilometers from Addis Ababa with an estimated population of about 267,350 of which 130,482 are males and 136,868 females. Out of which 222,276/83\%/ lives in the urban and the rest $17 \%$ live in rural area accordingly the city administration health office 2011/2012 plan/estimation.

The city administration was subdivided into 21 kebeles (9 urban and 12 rural). In the city administration, there is one government and two private hospital, one fistula hospital, 10 health center, 10 health posts and one regional research laboratory. Furthermore, there are one FGAE, one Maries tops, 28 private clinics and six diagnostic laboratories at different levels. In the city administration there are about 63,255 reproductive age /15-49/, 7,352 pregnant women, 7,352 under one years of age and 94/1000 (691) under one year of mortality will be estimated according to the Bahirdar city administration 2011/12 plan.

\subsection{Study Design}

The study design was institutional based cross sectional study at the government health centers and private pediatric clinics. Quantitative research methods were employed in the study which involved 608 sample of mothers interviewed using structured questioner.

\subsection{Study Participants}

The study subject was all mothers with infants six-twelve months age attending the government health centers and private pediatric clinics during the study period and selected based on the proposed sampling technique.

\subsection{Sample Size Determination}

Sample size adequate for determining the prevalence of non-exclusive breastfeeding among infants was computed using single population proportion formula with finite source population correction with the following assumption, in the calculation $95 \%$ confidence level, $5 \%$ margin of error and $10 \%$ compensation for possible non-response were assumed. To maximize the sample size, the previous study prevalence of exclusive breast feeding proportion was taken as $52 \%$ and ultimately sample size of 634 was determined.

\subsection{Sampling Procedures}

A multistage sampling technique was used in selecting the study participants. In the $1^{\text {st }}$ stage the study area were divided in to urban and rural health facilities. In the $2^{\text {st }}$ stage for logistical and cost reason, two health centers from 4 rural health center, three health centers from 6 urban health centers and two private pediatric clinics from 4 urban pediatric clinics were selected by simple random sampling technique. The number of samples was allocated proportional to the number of expected attendant mothers to represent each health center and private pediatric clinics. The eligible mothers who attend the health care unity were selected using a systematic random sampling technique until the sample size was offered. Here to determine the $\mathrm{n}^{\text {th }}$ interval, the average daily mother's attendants of each health care unity data were collected before the actual data collection. Based on the data on the average 15-20 mothers in the government health centers and 30-35 mothers in the private pediatric clinics were attended daily. So the data were collected in each health care unity's in every other three mothers based on their order of attendance.

\subsection{Data Collection Procedures}

A structured questionnaire was prepared for data collection. Prior to data collection questionnaires were prepared in English then translated in to Amharic and pretested in 15 mothers in areas not included in the survey but within the Bahir Dar city administration, that is Zenzelema and Shenbit health center, those vague questioners were corrected and administered.

Seven data collectors who have diploma and degree holder were selected in each health care unity which was currently employed there and have annual leave at the time of data collection (for the government employee) but not the private one and trained for one day on basic technique of interview. Participation in the study was in voluntary base and anonymity was maintained by the use of codes instead of names. Data collectors were approached and interviewed the selected respondents after informed consent was obtained. The collected data were checked every day for its completeness by the supervisor and principal investigator.

In addition to other questioners, Fifteen knowledge and ten attitudinal assessment questions on the duration, adequacy, episode and the many benefit of exclusive breast feeding were asked, recoded and computed to determine the mean value each so as to identify the respondents knowledge and attitude level towards exclusive breast feeding. 


\subsection{Study Variables}

The dependent variable of the study was Exclusive breast feeding. The independent variables include sociodemographic and economic characteristics (age, age of the infant, sex, income, educational status and marital status Religion, Ethnicity, place of residence, employment of mothers, work place), knowledge and attitude of mothers towards exclusive breast feeding and Maternal and child health condition.

The definition of exclusive breast feeding, the infant having received only breast milk during the $1^{\text {st }}$ six months from the mother without other liquids or solids except drops and syrups consisting of vitamins, mineral supplements, or medicines". Knowledge of mothers was assessed Those mothers who score mean value and above and below to questions asked on exclusive breast feeding importance, time and period of EBF called as adequate and inadequate knowledge.

The attitude of mothers on exclusive breast feeding practice those mothers who score mean value and above and below to questions of EBF importance, duration of EBF and disadvantages of not EBF considered as mothers had a Favorable Attitude and Unfavorable Attitude respectively.

\subsection{Data Management and Analysis}

The collected data were coded and entering using SPSS version 16.0 statistical package. Data cleaning was performed to check for frequencies, accuracy, consistencies, missed values and variables. Any error identified during data entry was being corrected after revision of the original completed questionnaire. All the data obtained from the study population were entered, cleaned and analyzed by the investigator.

To explain the study population in relation to relevant variables descriptive statistics was used. Associations between dependent and independent variables were assessed and its strength was presented using odds ratios and 95\% confidence intervals. Both bivariate and multivariate logistic regression was used to assess the association between outcome and explanatory variables. The effects of different independent variables were tested for their association with exclusive breast feeding by logistic regression analysis. The association of each explanatory variable with the dependent variable was checked individually using bi-variant analysis, and then variables with p-value less than 0.2 were entered into the multiple logistic regression analysis to control the confounders. Results were presented in tables and texts.

\section{Results}

\subsection{Socio-demographic Characteristics of Respondents}

Out of the total sample 634 eligible mothers, 608 were responded with a response rate of $95.9 \%$. The sociodemographic characteristics of the respondents were indicated in table 1 . The mean (SD) maternal age was 27.4 $( \pm 4.8)$ and a median of 27.0 years The majority of respondents was married (93.8\%) and followed by widowed
(3.6\%). Among the respondents of their current working status $304(50 \%)$ were house wife, $16 \%$ government employee, $15.6 \%$ farmer, $9.7 \%$ merchant, $6.7 \%$ daily laborer and $2 \%$ were private employee. Most of the mothers 225 (37\%) had unable to read and write Table 1

Table 1. Socio-demographic characteristics of respondents $(n=608)$ in Bahir Dar city administration North West, Ethiopia 2012.

\begin{tabular}{|c|c|c|c|}
\hline \multirow{2}{*}{ Variables } & \multicolumn{2}{|c|}{ Exclusively breastfeeding } & \multirow{2}{*}{ Percent } \\
\hline & Yes & No & \\
\hline \multicolumn{4}{|l|}{ Maternal age/years/ } \\
\hline $15-19$ & $3(20 \%)$ & $12(80 \%)$ & $15(100 \%)$ \\
\hline $20-35$ & $269(47.9 \%)$ & $293(52.1 \%)$ & $562(100 \%)$ \\
\hline $36-49$ & $12(38.7 \%)$ & $19(61.3 \%)$ & $31(100 \%)$ \\
\hline \multicolumn{4}{|l|}{ Area of resident } \\
\hline Urban & $255(52.4 \%)$ & $232(47.6 \%)$ & $487(100 \%)$ \\
\hline Rural & $29(24 \%)$ & $92(76 \%)$ & $121(100 \%)$ \\
\hline \multicolumn{4}{|l|}{ Maternal ethnicity } \\
\hline Amhara & $276(47 \%)$ & $311(53 \%)$ & $587(100 \%)$ \\
\hline Agew & $2(22.2 \%)$ & $7(77.8 \%)$ & $9(100 \%)$ \\
\hline Tigre & $5(71.4 \%)$ & $2(28.6 \%)$ & $7(100 \%)$ \\
\hline Oromo & $1(20 \%)$ & $4(80 \%)$ & $5(100 \%)$ \\
\hline \multicolumn{4}{|l|}{ Maternal religion } \\
\hline Orthodox & $234(47.8 \%)$ & $256(52.2 \%)$ & $490(100 \%)$ \\
\hline Muslim & $40(38.5 \%)$ & $64(61.5 \%)$ & $104(100 \%)$ \\
\hline Protestant & $10(71.4 \%)$ & $4(28.6 \%)$ & $14(100 \%)$ \\
\hline \multicolumn{4}{|l|}{ Marital status } \\
\hline Married & $280(49.1 \%)$ & $290(50.9 \%)$ & $570(100 \%)$ \\
\hline Divorced & $2(16.7 \%)$ & $10(83.3 \%)$ & $12(100 \%)$ \\
\hline Widowed & $2(9.1 \%)$ & $20(90.9 \%)$ & $22(100 \%)$ \\
\hline Single & $0(0 \%)$ & $4(100 \%)$ & $4(100 \%)$ \\
\hline \multicolumn{4}{|l|}{ Maternal education } \\
\hline $\begin{array}{l}\text { Unable to read and } \\
\text { write }\end{array}$ & $75(33.3 \%)$ & $150(66.7 \%)$ & $225(100 \%)$ \\
\hline Read and write & $13(39.4 \%)$ & $20(60.6 \%)$ & $33(100 \%)$ \\
\hline Primary education (1-8) & $67(53.2 \%)$ & $59(46.8 \%)$ & $126(100 \%)$ \\
\hline Secondary edu. (9-12) & $79(61.7 \%)$ & $49(38.3 \%)$ & $128(100 \%)$ \\
\hline College and above & $50(52.1 \%)$ & $46(47.9 \%)$ & $96(100 \%)$ \\
\hline
\end{tabular}

\subsection{Knowledge and Attitudinal p Proportion Towards to Exclusive Breast Feeding}

Among 608 respondent mothers who asked fifteen knowledge assessment questions towards exclusive breast feeding $365(60 \%)$ were adequate knowledge whereas 243 $(40 \%)$ were inadequate knowledge. Those respondents who were asked ten attitudinal questions towards exclusive breast feeding 295 (48.5\%) had favorable attitude and the rest 313 $(51.5 \%)$ were unfavorable attitude (Table 2$)$

Table 2. Knowledge and attitude of respondents on exclusive breast feeding in Bahir Dar city administration North West, Ethiopia 2012.

\begin{tabular}{lccl}
\hline \multirow{2}{*}{ Variables } & \multicolumn{2}{l}{ Exclusively breastfeeding } & \multirow{2}{*}{ percent } \\
\cline { 2 - 3 } & Yes & No & \\
\cline { 1 - 3 } Knowledge (mean=0.6003 & $\mathrm{SD}= \pm 0.490)$ & & \\
Inadequate knowledge & $58(23.9 \%)$ & $185(76.1 \%)$ & $243(100 \%)$ \\
Adequate knowledge & $226(61.9 \%)$ & $139(38.1 \%)$ & $365(100 \%)$ \\
Attitude (mean=0.815 SD= \pm 0.127$)$ & & \\
Favorable & $174(59 \%)$ & $121(41 \%)$ & $295(100 \%)$ \\
Unfavorable & $110(35.1 \%)$ & $203(64.9 \%)$ & $313(100 \%)$ \\
\hline
\end{tabular}




\subsection{Maternal and Infant Health Condition Affecting Exclusive Breast Feeding}

Among 608 respondent mothers 308 (50.7\%) infants were sick during the first six months and the rest $300(49.3 \%)$ were not sick. Among sick infants mothers who continued exclusive breast feed were $98(44.5 \%)$ and the rest 122
$(55.5 \%)$ were not continued. The majority of respondents 539 $(88.7 \%)$ were vaginal delivered and 69 (11.3\%) were caesarian section. The Majority of the respondents 579 $(95.2 \%)$ were very interested in breast feeding followed by not that much $12(2 \%)$, being a must $10(1.6 \%)$, no interest 6 $(1 \%)$ and others $1(0.2 \%)$ (Table 3$)$.

Table 3. Maternal and infant health condition affecting exclusive breast feeding in Bahir Dar city administration North West, Ethiopia 2012.

\begin{tabular}{|c|c|c|c|}
\hline \multirow{2}{*}{ variables } & \multicolumn{2}{|c|}{ Exclusively breastfeeding } & \multirow{2}{*}{ percent } \\
\hline & Yes & No & \\
\hline \multicolumn{4}{|c|}{ Was your infant sick during the first six months? } \\
\hline Yes & $121(39.3 \%)$ & $187(60.7 \%)$ & $308(100 \%)$ \\
\hline No & $163(54.3 \%)$ & $137(45.7 \%)$ & $300(100 \%)$ \\
\hline \multicolumn{4}{|c|}{ Should you continue breastfeeding? } \\
\hline No & $23(26.1 \%)$ & $65(73.9 \%)$ & $88(100 \%)$ \\
\hline Yes & $98(44.5 \%)$ & $122(55.5 \%)$ & $220(100 \%)$ \\
\hline \multicolumn{4}{|c|}{ Delivery type } \\
\hline Normal & $254(47.1 \%)$ & $285(52.9 \%)$ & $539(100 \%)$ \\
\hline $\mathrm{CS}$ & $30(43.5 \%)$ & $39(56.5 \%)$ & $69(100 \%)$ \\
\hline
\end{tabular}

Table 4. Proportion of mothers who started other feeds their infants before six months in Bahir Dar city administration North West, Ethiopia 2012.

\begin{tabular}{lll}
\hline Age of starting other feeds & Frequency & Percentage \\
\hline$<1$ month & 18 & 3 \\
2 months & 23 & 3.8 \\
3 months & 25 & 4.1 \\
4 months & 154 & 25.3 \\
5 months & 104 & 17.1 \\
6 months & 284 & 46.7 \\
Total & & 100 \\
\hline
\end{tabular}

From the total of 608 respondents 284 (46.7\%) had exclusively breast feed their infants for the first six months.

\subsection{Socio-demographic Factors Associated with Exclusive Breast Feeding}

Bi-variant analysis was done by applying chi-square test to asses any association between socio-demographic variables and exclusive breast feeding. The following were associated with exclusive breast feeding in bivarate analysis; Area of residence, maternal educational status, marital status, maternal current working status and work place.

Mothers whose area of residence in urban was more likely exclusively breastfeed than the rural residence $(\mathrm{OR}=3.486$ and $95 \% \mathrm{CI}$ : $0.182,0.451)$. Mothers whose educational status have unable to read and write were less likely exclusively breast feed their infants than able to read, write, primary school, secondary school, college and above educated mothers $(\mathrm{OR}=0.368$ and $95 \% \mathrm{CI}$ : $1.851,3.985)$. Mothers who are currently in union were more likely exclusively breastfeed than not currently in union mothers $(\mathrm{OR}=8.206$ and 95\% CI: 0.043, 0.348). Among the respondents of maternal current working status those house wife were more likely exclusively breastfeed than Government employee, farmer, merchant, daily laborer and private employee $(\mathrm{OR}=2.938$ and $95 \% \mathrm{CI}$ : $0.063,0.889)$. In this study, mothers of indoor working place were more likely exclusively breastfeed than out door and both place workers $(\mathrm{OR}=2.551$ and $95 \% \mathrm{CI}$ : $0.270,0.570)$. /detail in table 6 .

\subsection{Knowledge and Attitude of Mothers on Exclusive Breast Feeding}

Among 608 respondents of mothers who had adequate knowledge towards exclusive breast feeding was more likely exclusively breastfeed than inadequate knowledge $(\mathrm{OR}=5.186$ and $95 \% \mathrm{CI}(3.608,7.454)$. In this study mothers who had favorable attitude towards exclusive breast feed were more likely exclusively breastfeed than unfavorable attitude $(\mathrm{OR}=2.654$ and $95 \% \mathrm{CI}(1.1911,3.684)$.

\subsection{Maternal and Infant Health Condition Towards Exclusive Breast Feeding}

Among the respondents mothers whose infants were not sick during the first six months were more likely exclusively breastfeed than sick infants $(\mathrm{OR}=1.8$ and $95 \%$ CI 1.332, 2.538). Among sick infants mothers who were continued breast feed exclusively were less likely sick than not continued $(\mathrm{OR}=0.441$ and $95 \% \mathrm{CI}: 0.255,0.760)$. Mothers who delivered through vagina were less likely exclusively breastfeed than $\mathrm{CS}(\mathrm{OR}=0.863$ and $95 \% \mathrm{CI}$ : $0.521,1.430)$.

Table 5. Showed Socio-demographic factors of exclusive breast feeding in Bahir Dar city administration North West, Ethiopia 2012.

\begin{tabular}{llll}
\hline \multirow{2}{*}{ Variables } & \multicolumn{2}{l}{ Exclusively breastfeeding } & No \\
\cline { 2 - 4 } & Yes & & \\
\hline Maternal age/years/ & & 12 & $0.395[0.588,10.846]$ \\
$15-19$ & 3 & 293 & $1.453[0.328,1.444]$ \\
$20-35$ & 269 & 19 & 1 \\
$36-49$ & 12 & 95 & 1 \\
\hline
\end{tabular}




\begin{tabular}{|c|c|c|c|}
\hline \multirow{2}{*}{ Variables } & \multicolumn{2}{|c|}{ Exclusively breastfeeding } & \multirow{2}{*}{ COR (95\%CI) } \\
\hline & Yes & No & \\
\hline \multicolumn{4}{|l|}{ Area of resident } \\
\hline Urban & 255 & 232 & $3.486[0.182,0.451]$ \\
\hline Rural & 29 & 92 & 1 \\
\hline \multicolumn{4}{|l|}{ Maternal ethnicity } \\
\hline Amhara & 276 & 311 & $1.442[0.589,3.531]$ \\
\hline *Others & 8 & 13 & 1 \\
\hline \multicolumn{4}{|l|}{ Maternal religion } \\
\hline Orthodox & 234 & 256 & $1.243[0.536,1.207]$ \\
\hline$* *$ Others & 50 & 68 & 1 \\
\hline \multicolumn{4}{|l|}{ Marital status } \\
\hline Married & 280 & 290 & $8.206[0.043,0.348]$ \\
\hline$* * *$ Others & 4 & 34 & 1 \\
\hline \multicolumn{4}{|l|}{ Maternal education } \\
\hline -Unable to read and write & 75 & 150 & $0.368[1.851,3.985]$ \\
\hline -Read, write andPrimary education (1-8) & 80 & 79 & $0.745[0.891,2.017]$ \\
\hline -Secondary edu. (9-12), College and above & 129 & 95 & 1 \\
\hline \multicolumn{4}{|l|}{ Current working status } \\
\hline Government employee & 48 & 49 & $2.938[0.087,1.334]$ \\
\hline House wife & 178 & 126 & $4.238[0.063,0.889]$ \\
\hline Farmer & 17 & 78 & $0.653[0.374,6.252]$ \\
\hline Merchant & 24 & 35 & $2.057[0.119,1.983]$ \\
\hline Daily laborer & 14 & 27 & $1.555[0.150,2.761]$ \\
\hline Private employee & 3 & 9 & 1 \\
\hline \multicolumn{4}{|l|}{ Work place } \\
\hline Outdoors & 44 & 63 & $1.364[0.450,1.193]$ \\
\hline Indoors & 175 & 134 & $2.551[0.270,0.570]$ \\
\hline Both & 65 & 127 & 1 \\
\hline
\end{tabular}

$\mathrm{COR}=$ crude odds ratio $\mathrm{CI}=$ Confidence interval $*=$ Agew, Tigrie, Oromo $* *=$ Muslim, Protestant $* * *=$ Divorced, Widowed, Single

Table 6. Knowledge, attitude, maternal and infant health factors influencing exclusive breast feeding in Bahir Dar city administration North West, Ethiopia 2012 .

\begin{tabular}{|c|c|c|c|}
\hline \multirow{2}{*}{ Variables } & \multicolumn{2}{|c|}{ Exclusively breastfeeding } & \multirow{2}{*}{ COR (95\%CI) } \\
\hline & Yes & No & \\
\hline \multicolumn{4}{|l|}{ Maternal Knowledge } \\
\hline Inadequate knowledge & 58 & 185 & 1 \\
\hline adequate knowledge & 226 & 139 & $5.186[3.608,7.454]$ \\
\hline \multicolumn{4}{|l|}{ Maternal Attitude } \\
\hline Unfavorable & 110 & 203 & 1 \\
\hline Favorable & 174 & 121 & $2.654[1.1911,3.684]$ \\
\hline Yes & 121 & 187 & 1 \\
\hline No & 163 & 137 & $1.839[1.332,2.538]$ \\
\hline \multicolumn{4}{|l|}{ Delivery type } \\
\hline Normal & 254 & 285 & 1 \\
\hline $\mathrm{CS}$ & 30 & 39 & $0.863[0.521,1.430]$ \\
\hline
\end{tabular}

All Variables which have significant with Exclusive Breast Feeding in Bivarate analysis selected and entered multivariate logistic regression analysis to identify the most important factors of Exclusive Breast Feeding Among mothers who are currently in union were 0.2 times $(\mathrm{AOR}=0.176$ and $95 \% \mathrm{CI}$ : 0.058, 0.536) less likely exclusively breast feed than not currently in union mothers. Among respondents urban resident mothers were 0.4 times $(\mathrm{AOR}=0.375$ and $95 \% \mathrm{CI}: 0.211,0.664)$ less likely exclusive breast feed than rural resident mothers. In this study infants who were not sick during the first six months were 4.4 times $(\mathrm{AOR}=4.411$ and $95 \% \mathrm{CI}$ : 2.404 ,
8.094) more likely exclusively breastfeed than sick infants. Among sick infants mothers who continued exclusive breast feed were 0.4 times $(\mathrm{AOR}=0.355$ and 95\%CI: $0.192,0.658$ ) less likely not sick than not continued. Among respondents mothers who had adequate knowledge about exclusive breast feed were 3.6 times $(\mathrm{AOR}=3.570$ and $955 \mathrm{CI}: 2.367,5.383)$ more likely exclusively breast feed their infants than inadequate knowledge mothers. Mothers who had favorable attitude towards exclusive breast feed were 2.5 times $(\mathrm{AOR}=2.537$ and $95 \% \mathrm{CI}: 1.729,3.724)$ more likely exclusively breast feed their infant than unfavorable attitude mothers. 
Table 7. Factors associated with exclusive breast feeding in Bahir Dar city administration North West, Ethiopia 2012.

\begin{tabular}{|c|c|c|c|c|}
\hline Variables & Exclusively breastfeeding. $N=608$ & COR $(95 \% \mathrm{CI})$ & AOR (95\%CI) & p-value \\
\hline \multicolumn{5}{|l|}{ Marital status } \\
\hline Married & $280(46.0)$ & $8.206[0.043,0.348]$ & $0.176[0.058,0.536]$ & 0.002 \\
\hline$* *$ Others & $4(0.65)$ & 1 & 1 & \\
\hline \multicolumn{5}{|l|}{ Area of resident } \\
\hline Urban & $255(41.9)$ & $3.486[0.182,0.451]$ & $0.375[0.211,0.664]$ & 0.001 \\
\hline Rural & $29(4.76)$ & 1 & 1 & \\
\hline \multicolumn{5}{|l|}{ Infant sick } \\
\hline Yes & $121(19.9)$ & 1 & 1 & \\
\hline No & $163(26.8)$ & $1.839[1.332,2.538]$ & $4.411[2.404,8.094]$ & 0.0001 \\
\hline \multicolumn{5}{|l|}{ Maternal knowledge } \\
\hline Inadequate knowledge & $58(9.5)$ & 1 & 1 & \\
\hline adequate knowledge & $226(37.17)$ & $5.186[3.608,7.454]$ & $3.570[2.367,5.383]$ & 0.0001 \\
\hline \multicolumn{5}{|l|}{ Maternal attitude } \\
\hline Unfavorable & $110(18.09)$ & 1 & 1 & \\
\hline Favorable & $174(28.6)$ & $2.654[1.1911,3.684]$ & $2.537[1.729,3.724]$ & 0.0001 \\
\hline
\end{tabular}

$\mathrm{COR}=$ crude odds ratio $\mathrm{CI}=$ Confidence interval; $\mathrm{AOR}=$ Adjusted odds ratio

**Others=Divorced, Widowed, Single

\section{Discussion}

This institutional based study has attempted to the prevalence and factors associated with exclusively breast feeding among mothers with infants $6-12$ months of age.

Exclusive breast feeding for the first six months is identified as one of interventions to reduced infant morbidity and mortality in developing countries [28]. However, this study showed that $46.7 \%$ of mothers exclusively breast feed their infants. This is higher than a study conducted in Nigeria (16.4\%) [29], in Korea (35.4\%) [30]. This different might be in number of sample size, methodology difference, sociodemographic characteristics and cultural difference in the study area and another difference may be because of the health extension package implementation and use of health extension worker to promote EBF at the house hold level and the good commitment and promotion of the Government towards exclusive breast feeding. In contrarily this finding is less than study conducted in Ethiopia in 2011 (52\%) [1]. This might be due to socio-demographic characteristics and the difference in the awareness of the community. However, exclusively breast feeding prevalence is still very low as compared to the WHO recommendation.

In this study mothers who were currently in union were less likely exclusively breast feed their infants $(\mathrm{AOR}=0.176$ and $95 \% \mathrm{CI}$ : $(0.058,0.536)$. This is different from a study conducted in urban informal settlements, Nairobi Kenya in which women who were not in union, particularly those who were formerly married were more likely to stop breastfeeding their infants than women who were in union but consistent with a study conducted in Ethiopia 2009 [5]. It has been suggested that the association between marital status and breastfeeding cessation may be due to the presence or absence of social, emotional and economic support of a partner [31]. This might be due to the selection factors in the sample and possibly due to the fact that most of the mothers which were currently in union were better income, therefore can by alternative canned milk powder. Mothers living in rural areas were significantly more likely to exclusively breastfeed for longer than 6 months compared to mothers in rural areas. Urban women were more likely to wean earlier than rural women which was supported by other articles and reports $[24,32]$

In this study urban resident mothers were less likely exclusively breast feed their infants than rural resident mothers $(\mathrm{AOR}=0.375$ and $95 \% \mathrm{CI}:(0.211,0.664)$ which is similar with the above study but different with a study conducted in a rural and an urban area in Tanzania. with the aim of identifying factors related to early infant feeding practices. The study included 320 mothers from each area with infants below 7 months of age. Urban residence was positively associated with the duration of exclusive breastfeeding [24]. This might be in urban areas; there has been a gradual preference for bottle feeding and Often women cannot breastfeed as long as they would like due to changes in lifestyle (e.g., a mother who works outside the home may be apart more often from her baby) and also there is rumored that formula may be healthier for the baby. Breastfeed babies have fewer illnesses because human milk transfers to the infant into a mother's antibody to disease. About $80 \%$ of the cells in the breast milk are macrophages, cells that kill bacteria, fungi and viruses. Breastfed babies are protected in varying degrees, from a number of illnesses such as pneumonia, botulism, bronchitis, staph infection, influenza and ear infection [1]. A community based case-control study in Jimma, Ethiopia showed that the major effective child survival interventions, breast feeding and immunization were found to be major determinants of child survival. Pneumonia contributed to the largest deaths in the study population followed by acute diarrhea and malaria [33]. As the infants getting breast milk will develop an immune system and the chances of morbidity were less. In the present study infants which were not sick during the first six months were more likely exclusively breast feed (AOR $=4.411$ and $95 \% \mathrm{CI}$ $2.404,8.094$ ) and the likelihood of getting sickness were less. This might be the mothers were not started other feeds before the age of six months with various reasons like adequate knowledge and favorable attitude of the many benefit of 
exclusive breast feeding, family support and due attention of the commitment of the governments promotion towards exclusive breast feeding.

In the present study more than half of mothers were adequate knowledge $(60 \%)$ on the benefit of exclusive breast feeding and in this study mothers were practiced (46.7\%) breast feeding their infants exclusively for the first six months $(\mathrm{AOR}=3.570$ and $95 \% \mathrm{CI} 2.367,5.383)$. This study is similar with a study conducted in Jimma Arjo woreda (47.9\%) breast feed exclusively for the first six months [34] and lower than the report of EDHS 2011 (52\%) [5] and higher than with a study conducted in Peninsular Malaysia in 2011 (43.1\%) [11], Breast Feeding Practice among Medical Women in Nigeria 2011 (11.1\%) [35]. This might be when women are better educated, the opportunity for employment is eminent and thus the opportunity to stay at home and practice EBF is compromised. At the same time, since majority of the mothers were urban dwellers 487 (80.1\%) may be influenced by media advertising milk substitutes. The inverse relationship between maternal knowledge and breastfeeding is also found in other developing countries but is in contra-distinction to the western countries particularly, the USA, where for instance, higher maternal education is related to higher rates of EBF [9].

In this study less than half of the mothers were favorable attitude $(48.5 \%)$ on the benefit, importance, duration of EBF and advantages of EBF (AOR 2.537 and 95\%CI 1.729, 3.724). This might be the attitude of mothers may be influenced by cultural, social and economic factors which couldn't be changed through night even though they have adequate knowledge.

\section{Conclusion}

Exclusively breast feeding is significantly low in Bahir Dar city administration health care facility attendant mothers $(46.7 \%)$. Mothers who are currently in union, urban resident mothers, not sick infants, adequate knowledgeable mothers and favorable attitude mothers were significantly associated with exclusively breast feeding with (AOR 0.176, 0.375, $4.411,3.570,2.5370$ ) respectively.

\section{Recommendation}

Health promotion could be one of the possible interventions to increase mother's knowledge and attitude regarding to exclusive breast feeding.

\section{Acknowledgements}

We are grateful to university of Gondar to get this opportunity. We like to sincerely acknowledge the mothers of the infants for consenting to participate in the study. Our acknowledgement also goes to the data collectors, and the administration of the health institutions enrolled in the study.

We would like to thanks Dr. Gizachew Abdeta and Ewenat G/Hanna for their relevant, prompt and constructive comments during the whole research process. We will take this opportunity to thank Ato worku Awoke secretary of Amhara region Environmental Health association, Ato Metadel Adane Head \& Lecturer of Environmental Health Department Wollo University for their constructive comments.

\section{Funding Statement}

We have not received any finical support from any institution/government, hence, the operation of the research is solely financed by the handling fee received from the authors.

\section{Availability of Data and Materials}

The dataset analyzed during the current study is available from the corresponding author on reasonable request

\section{Author's Contribution}

E W. Was involved in preparing the research proposal, data analysis and research report, and revision of the manuscript

$\mathrm{AB}$ was involved in preparing, and revision of the manuscript.

\section{Ethics Approval and Consent to Participate}

Ethical clearance was obtained from the Institutional Review Board of university of Gondar, institute of public Health. Prior to data collection, informed consent was obtained from the mothers of the children.

\section{Competing of Interest}

We declares that there are no competing of interest

\section{References}

[1] Singh B. Knowledge, attitude and practice of breast feeding a case study. European jornal of scientific research. 2010; 40: 404-22.

[2] Organization WH. Infant and young child feeding: Model Chapter for textbooks for medical students and allied health professionals. 2009.

[3] Mihrshahi S IN, Shuaib M, Oddy W, Ampon R, Dibley MJ, et al. Prevalence of Exclusive Breastfeeding in Bangladesh and Its Association with Diarrhea and Acute Respiratory Infection. J Health Popul Nutr 2007; 25 (2): 195-204.

[4] International CaI. Ethiopia Demographic and Health Survey: key findings. 2012. 2011: 10.

[5] Alemayehu HJ, Habte D. Determinant of exclusive breastfeeding practices in Ethiopia. Ethiopian journal of health development. 2009; 23 no 1. 
[6] Haider J KH, Haile Mariam D and Demissie T. "Food and Nutrition" In Berhane Y, Haile Mariam D, Kloos H. The Epidemiology and Ecology of Health and Diseases in Ethiopia. Shama Books. 2006.

[7] Lande B AL, Baerug A, Trygg KU, Lund-Larsen K, Veierod $\mathrm{MB}$, Bjorneboe GE. Infant feeding practices and associated factors in the first six months of life. Acta Paediatrica. 2003; 92 (2): $152-61$.

[8] Jones G SR, Black RE, Bhutta ZA, Morris SS, Bellagio Child Survival Study Group. How many child deaths can we prevent this year. Lancet. 2003; 362: 65-71.

[9] Coutsoudis A PK, Kuhn L, Spooner E, Tsai WY, Coovadia HM, South African Vitamin A Study Group. Method of feeding and transmission of HIV-1 from mothers to children by 15 months of age. AIDS. 2001; 15 (3): 379-87.

[10] Desmond C BR, Boyce G, Coovadia HM, Coutsodis A, Rollins N, Newell ML. Scaling-up exclusive breastfeeding support programmes. Plops One. 2008; 3 (6): e2454.

[11] Illiff PJ PE, Tavengwa NV, Zunguza CD, Marinda ET, Nathoo KJ, Moulton LH, Ward BJ., Humphrey JH, ZVITAMBO study group. Early exclusive breastfeeding reduces the risk of postnatal HIV-1 transmission and increases HIV-free survival. AIDS. 2005; 19 (7): 699-708.

[12] International T. Factors associated with exclusive breastfeeding among infants under six months of age in peninsular Malaysia. Tan International Breastfeeding 2011; 6: 2.

[13] SG A. Water requirements of breast-fed infants in a hot climate. American Journal of Clinical Nutrition. 1978; 31 (7): 1154-7.

[14] G T. Programs to Protect, Support and Promote Breastfeeding Encyclopedia on Early childhood Development. 2004.

[15] UNICEF. Progress for children: a world fit for children. Statistical Review, Number 6. 2007.

[16] R Y. Universal health care and the removal of user fees. Lancet. 2009; 373: 2078-81.

[17] Anonymous. Effect of breastfeeding on infant and child mortality due to infectious diseases in less developed countries. Lancet. 2000; 355: 451-5.

[18] al Be. Effect of community-based promotion of exclusive breastfeeding on diarrhoeal illness and growth. Lancet. 2003; 361: 1418-23.

[19] book CWF. Ethiopian infant mortality rate. January 9. 2012.

[20] Aidam BA Pr-ER, Lartey A. Lactation counselling increases exclusive breast-feeding rates in Ghana. Journal of Nutrition 2005; 135 (7): 1691-5.

[21] Merten S A-LU. Exclusive breastfeeding rates and associated factors in Swiss baby-friendly hospitals. Human Lactation 2004; 20 (1): 9-17.
[22] Shirima R GT, Kylberg E, Gebre-Medhin M. Exclusive breast-feeding is rarely practised in rural and urban Morogoro, Tanzania. Public Health Nutrition 2000; 4 (2): 147-54.

[23] M. SYaM. Breast feeding practice among Employed Thai women In chiang Mai. Jornal of Human Lactaion. 1999; 15: 225-32.

[24] Shirima R G-MM, Greiner T. Information and socioeconomic factors associated with early breastfeeding practices in rural and urban Morogoro, Tanzania. Tanzania Food and Nutrition Centre. 2001; 90: 936-42.

[25] T G. Programs to Protect, Support and Promote Breastfeeding Encyclopedia on Early childhood Development. 2004.

[26] Molly Chisenga R, Lackson Kasonka M, Mpundu Makasa M, Moses Sinkala P, Chifumbe Chintu M, Christine Kaseba M, et al. Factors Affecting the Duration of Exclusive Breastfeeding among HIV-Infected and - Uninfected Women in Lusaka, Zambia. Jornal of Human Lactaion. 2009; 21: 3 266-75.

[27] Maria A. Quigley M, Yvonne J. Kelly, PhDb, Amanda Sacker, $\mathrm{PhD}$. Breastfeeding and Hospitalization for Diarrheal and Respiratory Infection in the United Kingdom Millennium Cohort Study. Official journal of the American academy of pediatrics. 2007; 119: 837-42.

[28] Edmond Km SC, Quigley Ma.. Delayed breast feeding initiation increases risk of neonatal mortality. Pediatrics. 2006; 117: 380-86.

[29] Kingsley E Agho MJD, Justice I Odiase and Sunday M Ogbonmwan3. Determinants of exclusive breastfeeding in Nigeria. BMC Pregnancy and Childbirth 2011; 11: 2.

[30] M. Kim Y-MKJ, -H. Yoo. Factors affecting exclusive breast feeding during the first six months in Korea.

[31] Elizabeth W Kimani-Murage NJM, Jean-Christophe Fotso, Catherine Kyobutungi, Martin K Mutua, Tabither M Gitau and Nelly Yatich. Patterns and determinants of breastfeeding and complementary feeding practices in urban informal settlements, Nairobi Kenya. BMC Public Health 2011; 11: 396.

[32] Dickson I. the association between breast feeding in Mongolia and geographical location of the mother and child 2012.

[33] Berhane\#2 BGaY. Children who were vaccinated, breast fed and from low parity mothers live longer: A community based case-control study in Jimma, Ethiopia. BMC Public Health. 2011; 11: 197.

[34] Dessalegn Tamiru TB, Eskindir Loha and Shikur Mohammed. Sub-optimal breastfeeding of infants during the first six months and associated factors in rural communities of Jimma Arjo Woreda, Southwest Ethiopia.. BMC Public Health 2012; 12: $363: 12-363$.

[35] A. E. Sadoh WES, and P. Oniyelu. Breast Feeding Practice among Medical Women in Nigeria. Niger Med J. 2011; 52 (1): $7-12$. 